\title{
Labile, recalcitrant and stable soil organic carbon: comparison of agronomic management in a vineyard of Trentino (Italy)
}

\author{
Raffaella Morelli ${ }^{1,{ }^{*}}$, Daniela Bertoldi $^{1}$, Daniela Baldantoni ${ }^{2}$, and Roberto Zanzotti ${ }^{1}$ \\ ${ }^{1}$ Technology Transfer Centre, Fondazione Edmund Mach, 38098 San Michele all'Adige, Italy \\ ${ }^{2}$ Department of Chemistry and Biology “Adolfo Zambelli”, University of Salerno, 84084 Fisciano, Italy
}

\begin{abstract}
The intensive exploitation of agricultural land has caused a depletion of soil organic carbon (SOC) and a decline in soil fertility, with a consequent decrease in the productivity of agroecosystems, also contributing to atmospheric GHG emissions. The ability of soil to storage organic carbon (OC) depends on its persistence and susceptibility to decomposition. SOC is generally partitioned into fractions differing in protection mechanisms and in turn decomposability. This study aimed to compare the OC pool repartition in soils managed with three different fertilization practices (mineral - CONV, manure - ORG$\mathrm{M}$ and green manure - ORG-GM) during a medium-term trial in vineyard, in order to understand the best solution in increasing $\mathrm{C}$ sequestration. The $\mathrm{OC}$ fractionation by acid hydrolysis allowed separating three fractions of OC: a labile, quickly mineralizable pool, a recalcitrant pool with a slower turnover and a stable pool protected by microbial attack. The results showed that the periodic application of organic matrices (manure and green manure), although did not increase total OC, enriched the soil along time with readily available $\mathrm{OC}$, thus promoting the release of nutrients. Green manure has also been shown to promote the accumulation of stabilized OC, able to improve the structure of the soil and, therefore, its fertility.
\end{abstract}

\section{Introduction}

In recent decades, the intensive exploitation of agricultural soils managed by unsustainable agronomic practices has caused a depletion of soil organic carbon (SOC). This has led to a decline in soil fertility and an alteration of biogeochemical cycles, with a consequent decrease in the productivity of agroecosystems. Additionally, agricultural land use contributes to climate changes with nearly $30 \%$ of all human carbon emissions [1]. Therefore, it is essential to encourage agricultural practices that promote soil carbon sequestration by contributing to the reduction of atmospheric emissions and improving the quality of agricultural soils.

Organic carbon (OC) storage depends on the balance between $\mathrm{C}$ additions and losses through organic matter decomposition [2]. The persistence of OC is a result of three main processes [3] that lead to stabilization: chemical resistance to decomposition, physical inaccessibility to microorganisms and enzymes and interactions with soil mineral components. SOC is generally partitioned into fractions differing in decomposability and protection mechanisms [3]. More labile OC fractions ensure substrates for the microbial community and nutrient availability for crops, refractory pools guarantee a long-term stock of nutrients and stable pools provide good soil structure and physic-chemical properties. Studying the OC pools and describing their relationships could improve the understanding of agronomic management effects on $\mathrm{C}$ dynamics.

Several studies have investigated on SOC sequestration in agricultural soils, comparing different agronomic practices, whereas literature lacks in studying on the fractionation of SOC in vineyard.

This study aimed to i) compare the OC repartition in pools with a different degree of stability to decomposition in soils managed with three different fertilization practices (mineral, manure and green manure) during a medium-term experimentation in vineyard and ii) identify the best solution in increasing $\mathrm{C}$ sequestration, in the face of a comparable productivity among agronomic managements (unpublished data).

\section{Materials and methods}

\subsection{Site description and soil collection}

The study was carried out in a vineyard of Pinot Blanc and Rhine Riesling located in Adige Valley (Trentino Region - $46^{\circ} 11^{\prime} 44^{\prime \prime} \mathrm{N}, 11^{\circ} 08^{\prime} 12^{\prime \prime} \mathrm{E}, 236 \mathrm{~m}$ a.s.l.). The grapevines were planted in 2009 on a SO4 rootstock arranged according to a "simple pergola trentina system" $(0.5 \mathrm{~m} \times 2.80 \mathrm{~m})$. The soil was loam, extremely calcareous, subalkaline and characterised by a good amount of organic matter and total N (Table 1). The samples of bulk soil were collected in four replicates per

* Corresponding author: raffaella.morelli@,fmach.it 
thesis between the rows into the $0-20 \mathrm{~cm}$ layer after one (2012) and seven (2018) years from the beginning of the trial.

Table 1. Soil characterization (mean values \pm SD) of the studied vineyard.

\begin{tabular}{|l|l|}
\hline Sand (g/kg d.w.) & $452 \pm 35$ \\
\hline Silt (g/kg d.w.) & $447 \pm 30$ \\
\hline Clay (g/kg d.w.) & $101 \pm 16$ \\
\hline pH & $7.9 \pm 0.1$ \\
\hline Total carbonates (g CaCO $3 /$ kg d.w.) & $468 \pm 80$ \\
\hline Active carbonates (g CaCO $3 /$ kg d.w.) & $12 \pm 2$ \\
\hline Organic matter (g/kg d.w.) & $38 \pm 7$ \\
\hline Total N (g/kg d.w.) & $1.5 \pm 0.3$ \\
\hline C/N & $14 \pm 2$ \\
\hline CEC (cmol+/kg d.w.) & $16 \pm 1$ \\
\hline
\end{tabular}

\subsection{Experimental plan}

The trial of agronomic management comparison has been set up since 2011. The vineyard was organized in randomized blocks, managed with three different protocols, corresponding to three theses: CONV (conventional management) ORG-M (organic management with manure) and ORG-GM (organic management with green manure). CONV thesis was fertilised yearly in spring with NPK 12-12-17, supplying $36 \mathrm{~kg} / \mathrm{ha}$ of mineral $\mathrm{N}$ on the row; the residues of pruning were left between rows. The rows of ORG-M thesis were amended with mature bovine manure every two years, providing $72 \mathrm{~kg} / \mathrm{ha}$ of total $\mathrm{N}$ and $1.2 \mathrm{t} / \mathrm{ha}$ of total $\mathrm{C}$ in two years; the pruning residues of the two ORG theses (ORG-M and ORG-GM) were added and matured within the manure heap. The inter-row of CONV and ORG-M theses was managed by green cover, regularly mowed during the spring-summer season. In the ORG-GM thesis, a winter green manure $(47 \%$ poaceae, $40 \%$ fabaceae, $13 \%$ brassicaceae) was applied every autumn on alternate inter-rows after the harvest at the dose of $180 \mathrm{~kg} / \mathrm{ha}$ of seeds. Every June, the green manure was chopped and laid down on the soil. The green manure produced on average a biomass of 0.70 $\mathrm{kg} / \mathrm{m}^{2} \mathrm{~d}$.w., containing $308 \mathrm{~g} / \mathrm{m}^{2}$ of total $\mathrm{C}$ and $20.4 \mathrm{~g} / \mathrm{m}^{2}$ of total $\mathrm{N}$, whereas the mean biomass of the permanent grass was $0.24 \mathrm{~kg} / \mathrm{m}^{2} \mathrm{~d}$.w., containing $101 \mathrm{~g} / \mathrm{m}^{2}$ of total $\mathrm{C}$ and $4.8 \mathrm{~g} / \mathrm{m}^{2}$ of total $\mathrm{N}$.

\subsection{Analytical procedures}

The analyses were performed on the air-dried fine fraction $(<2 \mathrm{~mm})$ of soil, except for total organic carbon (TOC) for which fine fraction was grinded $<0.2 \mathrm{~mm}$. TOC was obtained by the difference between total carbon, measured by Dumas combustion using a $\mathrm{CN}$ analyser equipped with a TCD detector, and inorganic carbon determined by volumetric method.

SOC was fractionated into pools with a different degree of susceptibility to decomposition. The procedure of acid hydrolysis [4] allows separating three fractions of OC: a labile, quickly mineralizable pool, a recalcitrant pool with a slower turnover and a stable pool protected by microbial attack. The first pool consists of promptly available substrates such as simple and complex sugars, proteins and hemicelluloses and it is hydrolysable in a weakly acid environment; the second pool is characterised by celluloses and carboxylic acids and it is hydrolysable in a strongly acid environment; the stable pool consists of a solid non-hydrolysable residue made of fatty acids, waxes, resins, suberin and lignin [5-6]. 30 $\mathrm{mL}$ of $2.5 \mathrm{M} \mathrm{H}_{2} \mathrm{SO}_{4}$ solution were added to $2 \mathrm{~g}$ of soil and incubated at $100{ }^{\circ} \mathrm{C}$ for 30 minutes. After cooling, the samples were centrifuged and the supernatant containing the labile fraction was removed and set aside. The solid residues were added with $2.5 \mathrm{~mL}$ of $13 \mathrm{M}$ $\mathrm{H}_{2} \mathrm{SO}_{4}$ solution and left stirring overnight at room temperature. The day after, the samples were added with $25 \mathrm{~mL}$ of distilled water and incubated at $100{ }^{\circ} \mathrm{C}$ for 3 hours. After cooling and centrifugation, the supernatant (the recalcitrant fraction) was recovered. The solid residue (the stable pool) was dried and its amount of OC was measured after dry combustion in excess of $\mathrm{O}_{2}$ by $\mathrm{CN}$ analyser. The $\mathrm{OC}$ of labile and recalcitrant liquid fractions was determined by TOC analyser with catalytic combustion and infrared detector.

\subsection{Data analysis}

The statistical analysis was performed by TIBCO Statistica ${ }^{\circledR}$ Software version 13.3 (2017) on the raw data. The differences in OC concentrations of the several pools among theses and sampling times were evaluated by Kruskal-Wallis non-parametric tests $(\alpha=0.05)$. The degree of relations between pools was appreciated by non-parametric Spearman correlation test. The graphical analysis was performed by the RStudio software version 1.2.1335.

\section{Results and discussion}

The amount of soil TOC neither grew nor decreased significantly in any of the three studied theses in seven years of trial (Table 2). Therefore, the losses from the system were balanced by the inputs of organic matter. Anyway, a different repartition of OC in fractions with different susceptibility to decomposition was observed along time.

Table 2. Soil TOC concentrations (mean \pm SD) after one and seven years from the beginning of the trial in the three investigated theses.

\begin{tabular}{|c|l|c|}
\hline Year & \multicolumn{1}{|c|}{ Thesis } & TOC (g/kg d.w.) \\
\hline \multirow{3}{*}{2012} & CONV & $24 \pm 3$ \\
\cline { 2 - 3 } & ORG-M & $21 \pm 2$ \\
\cline { 2 - 3 } & ORG-GM & $21 \pm 7$ \\
\hline \multirow{3}{*}{2018} & CONV & $26 \pm 6$ \\
\cline { 2 - 3 } & ORG-M & $22 \pm 3$ \\
\cline { 2 - 3 } & ORG-GM & $22 \pm 3$ \\
\hline
\end{tabular}


The labile OC fraction (Figure 1a) was significantly ( $\mathrm{p}<$ 0.05 ) increased by $14 \%$ in thesis ORG-M and $37 \%$ in thesis ORG-GM from 2012 to 2018 , whereas it was constant in CONV thesis. The recalcitrant fraction (Figure 1b) did not show statistical variations along time in the three theses because of the large variance of the data but, on average, this pool rose in both ORG-M $(59 \%)$ and ORG-GM (71\%). The stable OC fraction (Figure 1c), characterized by comparable concentrations among the theses in 2012, significantly $(p<0.05)$ increased $(29 \%)$ only in the thesis ORG-GM after seven years of trial, although also the trends in CONV and ORG-M were growing. Particularly, this tendency in CONV thesis, lacking an external input of organic biomass, could derive from recalcitrant ligninolytic residues of the pruning left between rows.

The obtained results have noticeable consequences on soil quality [7]. Indeed, green manure is able to supply OC for soil microbial community and consequently plant nutrients, deriving from the organic matter decomposition, carried out by decomposers. Moreover, green manure addition contributes to $\mathrm{C}$ stabilization in vineyard, improving not only soil chemical (fertility), but also soil physical (structure) characteristics. The findings are consistent with those of Garcia-Franco et al. [8], who found that green manure amendment, in combination with low tillage in a semiarid agroecosystem, determines an increase in $\mathrm{C}$ sequestration and an enhancement in soil fertility and structure, depending on OC incorporation and aggregate stabilization. Yao et al. [9] also found an increase in C stability in semiarid soils of a Chinese plateau treated by various mixes of one species of fabaceae and wheat, compared to a wheat control. On the contrary, Chaudhary and co-workers [10] showed a lower degree of $\mathrm{C}$ stabilization in soils treated with green manure compared to other treatments. However, in this case, green manure consisted of just one crop species, generally fabaceae or poaceae. This demonstrates the importance to select the right and balanced mix of seeds in order to promote $\mathrm{C}$ stabilization and consequently an improvement of soil quality. The mix of seeds used in the trial supplied refractory OC by residues of poaceae, more resistant to microbial decomposition, as well as more labile materials by fabaceae. It is demonstrated that labile substrates conduct at a higher SOM persistence in clayey silt fraction than less labile materials [11] and inorganic nutrients applied in farm soils increase the microbial efficiency in using $\mathrm{C}$ substrates as well as SOM formation and stabilization [12-13]. In this trial, such a hypothesis is supported by the positive correlation $\left(p<0.05 ; \rho_{S}=0.78\right)$ between stable and labile pools only for the ORG-GM thesis. Furthermore, the mean seasonal nitrate concentration (unpublished data), measured in 2018 in ORG-MG (9.2 $\pm 0.9 \mathrm{mg} / \mathrm{kg} \mathrm{d.w.})$ and supplied especially by biological $\mathrm{N}$ fixing, was higher $(\mathrm{p}<0.01)$ than nitrate provided and released in $\operatorname{CONV}(7.3 \pm 0.7$ $\mathrm{mg} / \mathrm{kg}$ d.w. $)$ and ORG-M $(5.7 \pm 0.7 \mathrm{mg} / \mathrm{kg} \mathrm{d.w.})$ theses. This evidence may have promoted the stabilization of soil OC in the ORG-GM thesis. The manure, although in spring 2018 was distributed on the row of ORG-M, contributed to significantly increase the available $\mathrm{C}$ in the whole vineyard, in association with the permanent grass between rows.

a
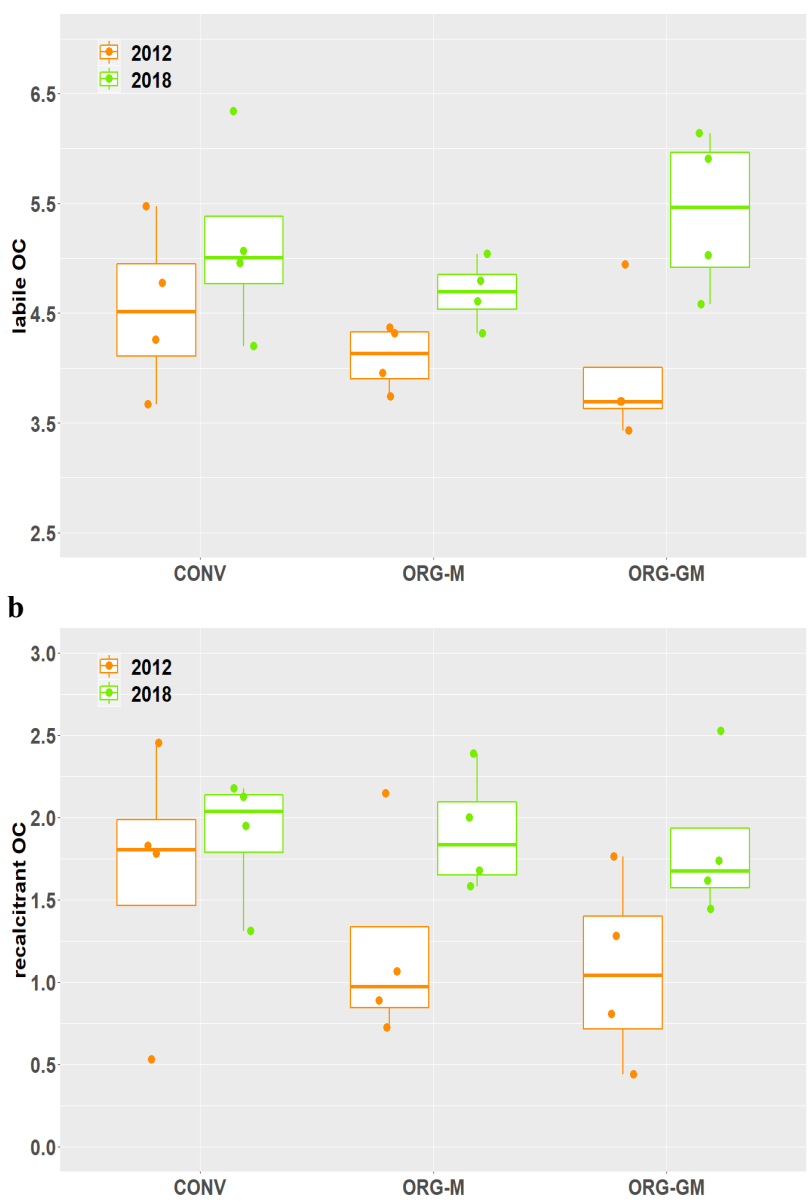

c

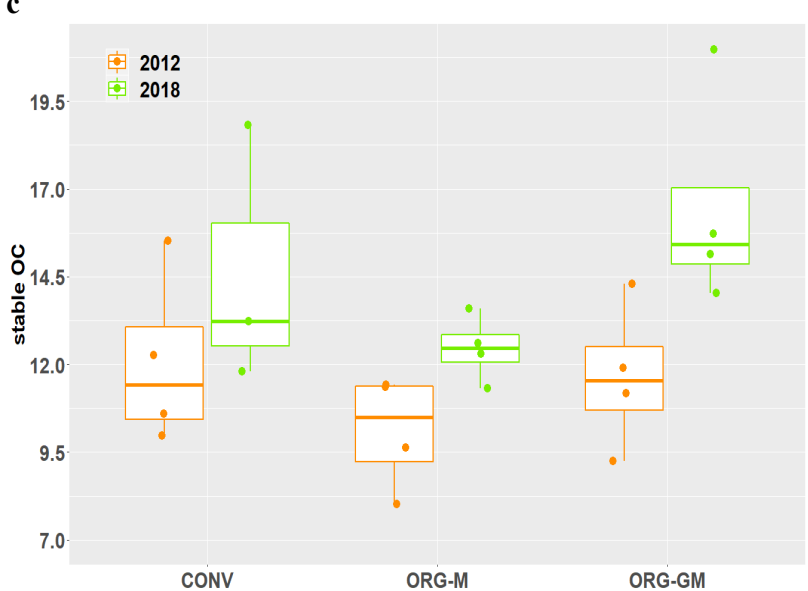

Figure 1. Labile (a), recalcitrant (b) and stable (c) pools of soil OC ( $\mathrm{g} / \mathrm{kg}$ d.w.) after one and seven years from the beginning of the trial in the three investigated theses.

The latter did not show the same effect in CONV, where mineral fertilizer was applied to the rows. Li et al. [14] found, in a 26-year long-term trial, that applying organic manure and organic manure combined with mineral fertilizer increased both labile fraction stocks and $\mathrm{C}$ sequestration in a wheat-maize rotation system in China. 


\section{Conclusions}

Studying the repartition into three OC pools with different degree of susceptibility to decomposition in a vineyard managed with different fertilization practices from 2011 to 2018, this research shed light on the ability of selected organic matrices in soil carbon sequestration. The results of the medium-term trial showed that the periodic application of organic matrices, such as manure and green manure, although does not increase TOC, enriches the soil with readily available OC, thus promoting the release of nutrients along time. Green manure has also been shown to promote $\mathrm{C}$ sequestration by accumulation of stabilized OC, able to improve the structure of the soil and, therefore, its fertility.

\section{References}

1. IPCC, AR5-Climate Change (2014)

2. R. Awale, A. Chatterjee, D. Franzen, Soil Tillage Res. 134, 213-222 (2013)

3. M.V. von Lützow, I. Kögel-Knabner, K. Ekschmitt, E. Matzner, G. Guggenberger, B. Marschner, H. Flessa, Eur. J. Soil Sci. 57, 426-445 (2006)

4. R.M. Hoosbeek, Y. Li, G.E. Scarascia-Mugnozza, Plant Soil 281, 247-254 (2006)

5. P. Rovira, V.R. Vallejo, Geoderma 107, 109-141 (2002)

6. K.K. Mclauchlan, S.E. Hobbie, SSSAJ 68, 16161625 (2004)

7. M.A. Shepherd, R. Harrison, J. Webb, Soil Use Manag. 18, 284-292 (2002)

8. N. Garcia-Franco, J. Albaladejo, M. Almagro, M. Martínez-Mena, Soil Tillage Res. 153, 66-75 (2015)

9. Z. Yao, Q. Xu, Y. Chen, N. Liu, L. Huang, Y. Zhao, D. Zhang, Y. Li, S. Zhang, W. Cao, B. Zhai, Z. Wang, S. Adl, Y. Gao, SSSAJ 83, 1722-32 (2019)

10. S. Chaudhary, G.S. Dheri, B.S. Brar, Soil Tillage Res. 166, 59-66 (2017)

11. K.T. Cyle, N. Hill, K. Young, T. Jenkins, D. Hancock, P.A. Schroeder, A. Thompson, Soil Biol. Biochem. 103, 138-148 (2016)

12. R.K Thiet, S.D. Frey, J. Six, Soil Biol. Biochem. 38, 837-844 (2006)

13. C.A. Kirkby, A.E. Richardson, L.J. Wade, G.D. Batten, C. Blanchard, J.A. kirkegaard, Soil Biol. Biochem. 60, 77-86 (2013)

14. J. Li, Y. Wen, X. Li, Y. Li, X. Yang, Z. Lin, Z. Song, J.M. Cooper, B. Zhao, Soil Tillage Res. 175, 281-290 (2018) 